Revista Iberoamericana, Vol. LXXI, Núm. 211, Abril-Junio 2005, 373-379

\title{
ÁNGEL RAMA Y LA GENERACIÓN CRÍTICA
}

\author{
POR \\ Rocío ANTÚNEZ \\ Universidad Autónoma Metropolitana-Iztapalapa
}

\begin{abstract}
Al revolver todas las mañanas en los recuerdos, yo no sé si precisamente manoteo entre ellos y por qué. O cómo es que revuelvo o manoteo en mi propia vida, aunque hable de otros.

Felisberto Hernández, Por los tiempos de Clemente Colling
\end{abstract}

En 1971, la editorial Arca de Montevideo publica La generación crítica, texto de Ángel Rama integrado por una serie de panoramas sobre la cultura uruguaya de los años treinta a los sesenta, donde alcanzan versiones definitivas una serie de tesis expuestas anteriormente en artículos periodísticos. Era la primera parte de un vasto abordaje al que se agregaría un segundo tomo con estudios particulares que el autor, entonces también director de la editorial, no llegó a reunir.

Probablemente lo mejor de la abundante producción intelectual de Rama no esté aquí. La mayoría de los estudiosos elegirían, entre sus numerosos aportes a la teorización de la cultura latinoamericana, la espacialización y temporalización del análisis cultural en su texto señero de 1984, La ciudad letrada; otros, en cambio, se inclinarían por las figuras transitivas de la transculturación formuladas a lo largo de diversos ensayos y concretadas en Transculturación narrativa en América Latina, de 1982. Y para contextualizar adecuadamente estos dos libros memorables habría que agregar su obsesivo discurrir a propósito de la modernidad y los procesos de modernización en nuestros países, principalmente en Rubén Darío y el modernismo (1970) y en Las máscaras democráticas del modernismo (1985). Quizás lo más valioso de su labor editorial no esté tampoco en Arca, modesta empresa uruguaya sin mayor distribución internacional, sino en la obra monumental que constituye la Biblioteca Ayacucho.

Antes de pasar a comentar la creación literaria de Ángel Rama, Mabel Moraña reseña su “sólida labor de investigador, crítico, periodista, antólogo”, y califica a las páginas de La generación crítica de "completísimo cuadro de un período crucial de las letras uruguayas” (201). Efectivamente, el título desata todo un inventario de nombres y breves caracterizaciones de figuras ubicadas en un mapa ordenado por un ojo capaz de ver la totalidad a la distancia. Pero en la multitud de nombres convocados falta uno, el del propio Ángel Rama, no sólo titular de la visión y del discurso que enuncia el panorama, sino 
también miembro de esta generación. Si colocamos en el centro la figura escamoteada del autor, el cuadro deviene paisaje de fondo; el texto, una versión de la historia compartida con los muchos nombrados, penetrando así en los terrenos de la autobiografía. Asimismo, es posible leer el texto de Rama como una línea de un debate donde los intelectuales opinantes componen una fisonomía, una historia y un destino para sí mismos y sus contemporáneos.

La generación comienza a manifestarse, según este ensayista, alrededor de 1940; termina su ciclo en 1969, y estaría integrada por dos promociones, cuya línea de separación ubica en el año 1955. La primera etapa sería internacionalista, la segunda nacionalista.

La primera promoción asoma a las letras a fines de la década del treinta y se consolida en los años cuarenta; sus fechas de nacimiento se aglomeran alrededor de 1920; en ella figuran algunos nombres que han proyectado la cultura uruguaya fuera de fronteras: en primer lugar, por ser el mayor en muchos sentidos, Juan Carlos Onetti (1909), seguido de Arturo Ardao, Carlos Real de Azúa, Carlos Martínez Moreno, Clara Silva, Armonía Somers, Mario Benedetti, Idea Vilariño, Manuel Claps, etc. Las fechas de nacimiento .de la segunda promoción van de 1926 a 1940; la integran, entre otros, Jorge Medina Vidal, Milton Schinca, Jorge Onetti, Marossa di Giorgio y, marcando el límite final, Eduardo Galeano (1940).

$\mathrm{Al}$ igual que en la mayor parte de sus textos, Rama vincula la cultura a la historia de la sociedad que la produce. Su relato es ambicioso, quiere nombrarlo todo: actores, factores nacionales e internacionales, económicos, políticos, sociales, culturales; las largas enumeraciones producen un efecto de apabullante completud.

Como todo relato generacional, éste se organiza sobre un paradigma temporal. Rama teje historia eslabonando fechas; el hito de 1955 refiere al comienzo de la crisis económica nacional detectada por la Comisión de Inversiones y Desarrollo Económico (CIDE), de ahí que llame a la segunda “promoción de la crisis”. El término del ciclo, 1969, remite al primer aniversario de la muerte del Che Guevara, celebrado por la guerrilla tupamara con la toma de la ciudad de Pando. Si recordamos que el libro como tal apareció en 1972, este acto de presencia de la guerrilla era un acontecimiento reciente, de apenas ayer en el momento de la escritura; Rama lo atrapa al vuelo, con la celeridad típica de una conciencia lúcida, formada en la práctica del periodismo, y lo convierte en frontera entre dos épocas.

Aunque el autor no hace distingos, me inclino a subrayar la preponderancia de la primera promoción en esta historia. Entre los que-siguiendo a Carlos Real de Azúa-Rama llama “jefes de fila y supervivientes”, se encuentra el economista Carlos Quijano (1900), fundador de la tribuna más importante de la Generación, el semanario Marcha, y su director desde su aparición en 1939 hasta su clausura por la dictadura militar, en 1974; Rama cita algunos de los editoriales de Quijano en diversas oportunidades, concediéndole así un lugar de autoridad con respecto a su propio discurso. Y a la lista de nombres de la primera promoción habría que agregar los del propio Ángel Rama (1926) y el de su frecuente adversario en los debates literarios, Emir Rodríguez Monegal (1921).

Con este crítico y con otros autores de los relatos generacionales dialoga el libro de Rama con respecto al nombre adjudicado a la generación (y ya sabemos que, en nuestra cultura, la elección de un nombre implica también la de una historia y un destino). 
En su Literatura uruguaya del medio siglo, libro publicado en 1966, Emir Rodríguez Monegal parte de la emergencia evidente de un grupo generacional hacia 1945, con lo que inclina la balanza a favor de su propia denominación, "generación del 45”. Pero ubica sus primeras manifestaciones hacia 1940, acercando así el comienzo de su propia versión del relato a la fundación del semanario Marcha, dos puntos en que coinciden los diversos narradores.

Hay coincidencia en casi todos con respecto a lo que puede llamarse fecha de iniciación del grupo. Esa fecha es 1940, es decir a sólo medio año de la fundación de Marcha. Tal fecha básica -que marca el comienzo del período de gestación del grupo, es decir: el momento en que irrumpe en la vida literaria y comienza a polemizar con la generación anterior para hacerse sitio- fue indicada ya en un artículo de 1952 sobre La nueva literatura nacional (Marcha, diciembre 26), fue adoptada también por Carlos Real de Azúa, Un siglo y medio de cultura uruguaya [...] (Montevideo, 1958), por Ángel Rama (Testimonio, confesión y enjuiciamiento de 20 años de Historia literaria y de nueva Literatura uruguaya; artículo que publicó Marcha en julio de 1959) y por Mario Benedetti en un trabajo (finalmente titulado La literatura uruguaya cambia de voz) que empezó a publicarse oralmente en enero 1962 y alcanzó su versión definitiva en el libro Literatura Uruguaya siglo Xx (Montevideo, 1963), de su autor (33).

Tanto Rodríguez Monegal como los intelectuales a quienes cita, leen la literatura como producto de una cultura determinada por factores históricos y políticos. Con ligeras variantes, ubican la escena de sus orígenes en un momento de crisis histórica marcada, en el ámbito nacional, por el golpe de Estado de Gabriel Terra del 31 de marzo de 1933 y ahondada luego en lo internacional con la Guerra Civil Española, y la Segunda Guerra Mundial.

Así, Carlos Real de Azúa reflexiona no sólo sobre la política en un sentido amplio, sino también sobre la política partidaria en El impulso y su freno, texto de análisis políticocultural de 1964, con el cual también dialoga La generación crítica. Este ensayista realiza un interesantísimo análisis del batllismo, la fracción del Partido Colorado que, según diversos historiadores y el imaginario colectivo que los constituye, completó el proceso de modernización del Uruguay en la primera mitad del siglo xx. En sus propias filas se gestó también el golpe de Estado del 31 de marzo de 1933; para la generación que lo vivió, la prueba fehaciente de que la "democracia perfecta" albergaba en sus entrañas las semillas de fascismo y totalitarismo que brotaban simultáneamente en la Europa de entreguerras y en varios países latinoamericanos. El estancamiento de la vida nacional se hace evidente, según Real, con la emergencia de esta generación, alrededor de 1945, fecha desde donde es posible visualizar, con suficiente distancia histórica, tanto el impulso como su freno:

En realidad, cuando cayó el Batllismo en 1933, barrido por un golpe de Estado tramado, empujado desde sus propias filas, el Uruguay, que había contribuido a modelar, estaba demasiado cerca como para jerarquizar lo sustancial de lo accidental. [...] Por eso fue después de 1945 -una fecha que suele aceptarse como hito simbólico de emergencia de una nueva generación- que empezaron a verse el, o los problemas. [...] El mismo diagnóstico de nuestros países, que los economistas del desarrollo comenzaban a esbozar en estos años, se hizo presente para nosotros en todas las manifestaciones de la vida 
nacional. Todavía no se desplegaba la triste elocuencia de las cifras y de porcentajes pero, por delante de ellas, todo cobraba una apariencia de fraude, de presunción, de quiero y no puedo, de complicidad vergonzante y equívoca. Era lo mismo si mirábamos lo político ("la democracia perfecta”) que lo social ("el laboratorio del mundo"), que lo cultural ("la Atenas del Plata”), que lo económico (“el país pequeño pero rico”). (16-17)

Por su parte, Mario Benedetti postula la consideración de los aspectos políticos al nivel de la metodología del análisis de la cultura: “Como en todos los rincones de América Latina, en el Uruguay el fenómeno político ha mediatizado importantes aspectos de la vida cultural. Hoy en día resulta difícil entender lo que culturalmente sucede en el Uruguay, si no se atan ciertos cabos del proceso político” (38). De la política, erigida como antecedente, se trasladan a la escena de la cultura, donde suelen representar un sujeto que experimenta una toma de conciencia concebida como el desenmascaramiento de una realidad velada, como un quiebre de las ilusiones y valores en los que se formaron. Este quiebre, cuya raigambre política subrayan para luego exponer sus consecuencias éticas y estéticas, constituye el eje de sus autorrepresentaciones. Al igual que Rama, allí ubican el cierre de un ciclo histórico-cultural y el comienzo de otro, caracterizado por una nueva sensibilidad. "La literatura uruguaya cambia de voz”, afirmará Mario Benedetti al reconstruir el proceso en los años sesenta, y el primer subtítulo del texto de Rodríguez Monegal (1966) es "La toma de conciencia” (13).

En esta línea de lectura política del proceso cultural, Rama rechaza la denominación “del 45”, pues esta fecha no alude -en su opinión- a ningún suceso crucial; descarta asimismo la de "generación de Marcha", que sin duda hubiera empequeñecido el panorama limitándolo al grupo vinculado con el semanario. Elige, en cambio, un nombre cargado de significaciones, "generación crítica”, ya que alude a la asunción de una conciencia crítica en todos los ámbitos de la actividad intelectual y estética:

Tal conciencia corresponde a una óptica para ver la realidad, pero no tiene ninguna vinculación forzosa con estilos literarios (realismo) ni con filosofías (marxismo), pudiéndose en cambio comprobar que abraza muy dispares orientaciones. Tampoco puede ser equiparada, como en las tesis luckasianas, a un perspectivismo, es decir, a un finalismo que gobierna la comprensión del presente, porque, al contrario, parece más bien nacer de una desilusión -donde puede estar implícita la quiebra de un ideal- lo que confiere especial relevancia a la experiencia existencial, a la lección histórica del hoy. ( $\mathrm{La}$ generación 33).

A partir de esa toma de conciencia, la actitud de estos intelectuales se caracterizará por un rasgo definidor: la crítica, punto en el cual coinciden los diversos autores del relato generacional. Rama la eleva al nivel de cualidad constitutiva al elegir ese nombre que, según sus palabras, “atiende al signo dominante de la cultura de esa época”, la "conciencia crítica”. Su relato se organiza alrededor de un pronombre que lo incluye y de la angustia de la interrogación acerca de lo propio:

La pregunta que nos dirige el extranjero no es demasiado distinta de la que se ha venido formulando el hombre común uruguayo, aunque éste, obviamente, con mayor desconcierto 
y emoción: ¿Qué nos ha pasado? ¿Por qué hemos llegado a esto? ¿Cómo fue que se nos perdió aquel Uruguay? ¿Cómo se concluyó así, tan de golpe, el bienestar, el civilismo, la democracia? [T] tocamos el corazón del desconcierto: la nostalgia de un idealizado paraíso, ya perdido; el empecinamiento con que se sale a preguntar por algo que ya no existe; el matiz desvalido o rencoroso con que se le piden cuentas al pasado. (11)

La voz del intelectual parece acoger los ecos de la voz popular para colorear con matices afectivos -"desconcierto y emoción”- el interior del espacio nacional. Las preguntas de Rama, así como sus respuestas, se encaminan por el rumbo seguido por otros integrantes del "nosotros" generacional: la línea recta y ascendente de la historia oficial se ha quebrado, y en el espacio de la fisura brota la dimensión política de los hechos culturales.

Rama asocia la toma de conciencia que politiza a su generación no tanto con el golpe de Estado de 1933, sino con la restauración democrática de 1938, en que los integrantes observan que las estructuras anteriores a esta conmoción han permanecido intactas luego de la restauración. Serían los escritores quienes mejor detectarían ese proceso, por lo cual los elige como eje de su trabajo, aunque también considera colateralmente la obra de economistas, periodistas, artistas plásticos y otros intelectuales. Manejaba entonces la concepción de las élites intelectuales como maestros de la sociedad, cuyas enseñanzas penetran en el cuerpo social, figura de estirpe rodoniana que le acompaña en diversos textos.

La propia sintaxis de su discurso vincula una autoridad indiscutible en el terreno del análisis político, Carlos Quijano, y un exponente maestro en el de la creación: Juan Carlos Onetti. En textos críticos sobre Onetti, como “Origen de un novelista y de una generación literaria”, de 1965, y “El narrador ingresa al baile de máscaras de la modernidad”, de 1983, el relato de orígenes comienza citando un párrafo de un editorial de Carlos Quijano que se reproduce también en La generación crítica, para respaldar la hipótesis que hace coincidir restauración democrática y desenmascaramiento del estatismo, hacia 1938. ${ }^{1}$

El 31 de marzo es un recodo de nuestra historia; pero no lo es menos y acaso lo sea más, el año 1938. En este último, con más claridad que en aquella fecha -se tarda a veces en comprender el cabal significado de los hechos aunque pueda intuírsele- la historia del país se bifurcó. El 31 de marzo fue la reacción encabezada por las clases dominantes y más capaces. 1938 mostró que la resistencia al golpe de Estado había equivocado el camino. Para vencer a la reacción no se podía transitar por los mismos caminos de ella, buscar el apoyo de las mismas fuerzas que había reclamado el golpe o lo habían tolerado. El tiempo, bien corto por cierto, no tardó en demostrarlo. Cuando los núcleos políticos desalojados el 31 de marzo volvieron al gobierno, dejaron en pie no sólo las estructuras que habían posibilitado el golpe, sino también las propias construcciones de la dictadura. Se reinstalaron en el edificio conservado o reacondicionado o adornado por ésta. Todo siguió como antes y la lucha que contra la reacción se inició el 31 de marzo, en vez de abrir nuevas alternativas al país, se diluyó en una oscura confusión. (39)

\footnotetext{
${ }^{1}$ Se trata de un párrafo del editorial de Quijano publicado en Marcha 1248, del 26 de marzo de 1965.
} 
Pero 1939 no es sólo el año en que la Guerra Civil Española desemboca en la Segunda Mundial, y el primero del “aquí no ha pasado nada”, sino también el año de publicación de El pozo. Y Eladio Linacero sale a escena para representar un acto de escritura donde, entre otras cosas, se vacía el relato de los orígenes nacionales:

Fuera de todo esto, que no cuenta para nada, ¿Qué se puede hacer en este país? Nada, ni dejarse engañar. Si uno fuera una bestia rubia, acaso comprendiera a Hitler. Hay posibilidades para una fe en Alemania; existe un antiguo pasado y un futuro, cualquiera que sea. Si uno fuera un voluntarioso imbécil se dejaría ganar sin esfuerzos por la nueva mística germana. ¿Pero aquí? Detrás de nosotros no hay nada. Un gaucho, dos gauchos, treinta y tres gauchos. (39)

Sin duda, este hombre que en 1939 cumple 40 años y para celebrarlo se pone a escribir su autobiografía, es una presencia mayor para la generación de Rama. Viene de atrás, de las primeras décadas del siglo, en las que se urdieron los relatos monumentalizantes de la historia uruguaya para las celebraciones del Centenario de la Independencia, diseminadas entre 1925 y 1930. Según el historiador Gerardo Caetano, se consolida entonces una fuerte propuesta simbólico-política orientada a dejar una huella importante y perdurable en los sentimientos de pertenencia cívica de los ciudadanos uruguayos. Se narra un siglo de la historia del país como el pasado de un proyecto cuya cima se alcanza en ese preciso momento, y se le adjudica una temporalidad progresiva, sin quiebres ni retrocesos importantes en lo concerniente al pasado, mientras se vislumbra un futuro aún mejor, con una tonalidad segura y optimista.

Pocos años después, las huellas de estos relatos monumentalizantes se leen, ya fisuradas, en los discursos sobre el país y su cultura. A la distancia de una generación, Rama y sus contemporáneos pudieron contemplar tanto la “democracia perfecta” como su quiebre; el laboratorio donde se exhibía el “crisol de razas” junto a las leyes de indeseables que acabaron con la inmigración espontánea.

¿Cuánto de elección de una trayectoria personal hay en la elección de un nombre como el de generación crítica? ¿Hasta qué punto la escritura de esta serie de ensayos determina el punto de mira a través del cual se ha de percibir la totalidad del continente durante este período? Con singular lucidez anota Ángel Rama en La ciudad letrada:

Esta recorrida que hasta aquí ha procurado caracterizar la ciudad letrada según sus seculares avatares, va a pasar ahora de historia social a historia familiar, para recaer por último en cuasi biografía, anunciando la previsible entrada de juicios y prejuicios, realidades y deseos, visiones y confusiones, sobre todo porque la percepción culturalista que hasta aquí me ha guiado, al llegar a los suburbios del presente concede primacía a otro obligado componente de la cultura, que es la política. (114-15).

La teorización del lugar de los letrados en las ciudades latinoamericanas, que parte de figuras de conocimiento de índole foucaultiana como la ciudad espacio -del- poder y del poder-saber, desemboca en la "ciudad politizada” y la “ciudad revolucionada”; quizás extrapolaciones hacia el panorama continental de ese corte doloroso, de esa toma de 
conciencia donde se desvanecieron muchas de las imágenes de nación a las que abrieron los ojos los miembros de la generación crítica.

Quisiera por último destacar la inmensa productividad de esta generación, la de nuestros maestros. Muchos de sus integrantes viven, piensan, escriben en este mismo momento. Y en la relación cara a cara o en las lecturas, quienes ahora ejercemos la docencia y la crítica literaria o de la cultura, difundimos o reescribimos sus relatos generacionales.

\section{OBRAS CITADAS}

Benedetti, Mario. "La literatura uruguaya cambia de voz”. Literatura uruguaya; siglo Xх. 2 ed. Montevideo: Alfa, 1969. 9-45.

Caetano, Gerardo. "Lo privado desde lo público. Ciudadanía, nación y vida privada en el Centenario”. Historias de la vida privada en el Uruguay; v.3, Individuo y soledades, 1920-1990. José Pedro Barran, Gerardo Caetano y Teresa Porzecanski, directores. Montevideo: Taurus, 1998. 17-61.

Moraña, Mabel. "La narrativa de Ángel Rama”. Memorias de la generación fantasma. Montevideo: Monte Sexto, 1988.

Onetti, Juan Carlos. El pozo. Seguido de "Origen de un novelista y de una generación literaria”, por Ángel Rama. Montevideo: Arca, 1973.

Rama, Ángel. La ciudad letrada. Montevideo: Fundación Internacional Ángel Rama, 1984.

La generación crítica; 1939-1969. Montevideo: Arca, 1972.

Real de Azúa, Carlos. El impulso y su freno, tres décadas de batllismo y las raíces de la crisis uruguaya. Montevideo: Ediciones de la Banda Oriental, 1964.

Rodríguez Monegal, Emir. Literatura uruguaya del medio siglo. Montevideo: Alfa, 1966. 